\title{
MATERIAis E CRIAÇÃO EM DESIGN E ARQUitetura: COMPARTILHANDO EXPERIÊNCIAS PARA A ECONOMIA CRIATIVA
}

\author{
Denise Dantas \\ Cristiane Aun Bertoldi \\ Cibele Haddad Taralli
}

\begin{tabular}{|c|c|}
\hline I IO & ${ }^{1} \mathrm{O}$ projeto conta com \\
\hline in & $\begin{array}{l}\text { pronrama Ciência sem } \\
\text { Visitante - Especial. O evento } \\
\text { contou também com apoio da } \\
\text { PROCEU- USP. }\end{array}$ \\
\hline & $\begin{array}{l}{ }^{2} \text { Atualmente é professora } \\
\text { visitante especial na FAU USP } \\
\text { entre } 2015 \text { e } 2017 \text {. }\end{array}$ \\
\hline
\end{tabular}

\section{INTRODUÇÃO}

Entre 5 e 23 de setembro de 2016 a Faculdade de Arquitetura e Urbanismo da Universidade de São Paulo sediou o evento Materiais e Criação em Design e Arquitetura: compartilhando experiências para a economia criativa. Este evento foi organizado em parceria entre o LabDesign FAU USP e o Materiali e Design, do Politecnico di Milano, como parte das atividades do projeto Pesquisa em materiais e inovação para aplicação nas indústrias criativas nos campos do design e da arquitetura: a experiência do Politecnico di Milano trazida para o contexto brasileiro ${ }^{1}$. As atividades contaram com a presença da Profa. Dra. Barbara Del Curto ${ }^{2}$, docente e pesquisadora na área de materiais para o design e coordenadora do acervo Materiali e Design, materioteca na mesma instituição em funcionamento desde o ano 2000. Em sua segunda visita ao Brasil, a professora apresentou sua experiência em pesquisa e projetos nesta área, permitindo intercâmbio entre pesquisadores, universidades, profissionais e empresas. 0 evento contou com diversas atividades que se desenvolveram tanto na Vila Penteado, sede do Programa de Pós-Graduação da instituição, como no edifício anexo do Vilanova Artigas, na cidade Universitária. Iniciou-se na semana de 5 a 9 de setembro com 0 workshop Design e materiais - Experimentações com cores e texturas para criação de produtos cerâmicos, na Seção Técnica de Modelos e Ensaios e Experimentações Construtivas, a STMEEC. Na semana de 19 a 23 de setembro, na Vila Penteado, ocorreram mesas de debate em Arquitetura, Brinquedos e Jogos, Cerâmica, Embalagem, Joalheria, Mobiliário e Têxtil e Moda. Estes temas foram selecionados por sua relevância na economia brasileira e italiana, bem como por contemplar as pesquisas desenvolvidas pela professora Barbara e pelos pesquisadores do LabDesign FAU USP. Contando com trinta e seis convidados nas sete áreas do conhecimento acima, os debates levantaram questões relacionadas à pesquisa em materiais e sua aplicação no design e na arquitetura considerando novas tecnologias e processos produtivos, modelos de parceria empresas-universidade, as exposições como ferramentas de comunicação de pesquisas e seus resultados. 0 evento reuniu profissionais, pesquisadores, representantes de entidades e associações, empresas brasileiras e universidades, para permitir debates que pudessem mostrar os diversos pontos de vista sobre as possibilidades de maior 
3 Professora do Curso de Design e do LabDesign FAU USP, desenvolve pesquisa em materiais cerâmicos

4 Professora do Curso de Design e coordenadora do LabDesign FAU USP.

${ }^{5}$ Discente do curso de design da FAU USP. articulação entre estes atores. Também foram abordados os aspectos de rebatimento dos resultados das pesquisas para os pequenos e médios empresários da economia criativa. A professora Barbara proferiu nove apresentações durante a semana de debates, todas com ênfase em seu trabalho de pesquisa no grupo NextMaterials, no Politecnico di Milano e em suas atividades didáticas na graduação e pós-graduação.

\section{DESign e MATERIAis - EXPERIMENTAÇÕes COM CORES E TEXTURAS PARA CRIAÇÃO DE PRODUTOS CERÂMICOS}

O workshop Design e materiais - Experimentações com cores e texturas para criação de produtos cerâmicos aconteceu de 5 a 9 de setembro de 2016, com 24 horas de duração, no Laboratório da STMEEC - Seção Técnica de Modelos Ensaios e Experimentações Construtivas da FAU USP. Sua organização envolveu as professoras Cristiane Aun Bertoldi ${ }^{3}$, Barbara Del Curto e Denise Dantas $^{4}$ e a monitora Stephani Takahashi ${ }^{5}$. Teve a participação de dezessete alunos de graduação em design. A proposta do workshop baseou-se no modelo utilizado no Politecnico de Milano que reúne empresa e academia no desenvolvimento de propostas inovadoras em design e materiais, vislumbrando resultados para possível uso por agentes da economia criativa. No modelo italiano, a empresa parceira apresenta o briefing, fornece materiais e aplica o workshop, sob a supervisão da professora Barbara, que orienta os procedimentos metodológico para a realização de experimentações, ensaios e análises de resultados. No modelo brasileiro, a empresa parceira, Grupo Fragnani, forneceu informações sobre sua estratégia de negócios focada na eficiência produtiva e baixo custo, os processos de fabricação, as características dos materiais empregados e dados referentes a limites para desenvolvimento de novos produtos, pautados nas restrições de fabricação, exemplificados nas amostras fornecidas. Durante o workshop ministrado pela professora Cristiane foram desenvolvidos projetos de revestimentos cerâmicos para aplicação em fachadas e paredes, com obtenção de protótipos de cerâmica a partir de:

a) experimentação com materiais cerâmicos e criação de novas formulações de massa;

b) criação de padrões com relevos cuja qualidade estética é acentuada pela incidência da luz na superfície vertical do assentamento.

Quanto ao desenvolvimento de novos materiais, foram criadas trinta e sete formulações de massas cerâmicas tanto com coloração na massa, decorrente da adição de corantes e óxidos cerâmicos, quanto com texturas variadas originadas pela adição de cargas orgânicas e minerais não metálicas. Em relação aos padrões, foram criados quarenta e oito modelos a partir de processos digitais e analógicos de projeto e produção dos protótipos. As peças foram queimadas, resultando em mais de 80 protótipos de revestimentos cerâmicos de $10 \times 10 \mathrm{~cm}$ com cores, texturas e relevos variados. A avaliação visual dos protótipos evidenciou um rol surpreendente de potencialidades para desenvolvimento de novos produtos pela indústria. Este fato foi endossado por participantes da Semana de Debates de 19 a 23 de 


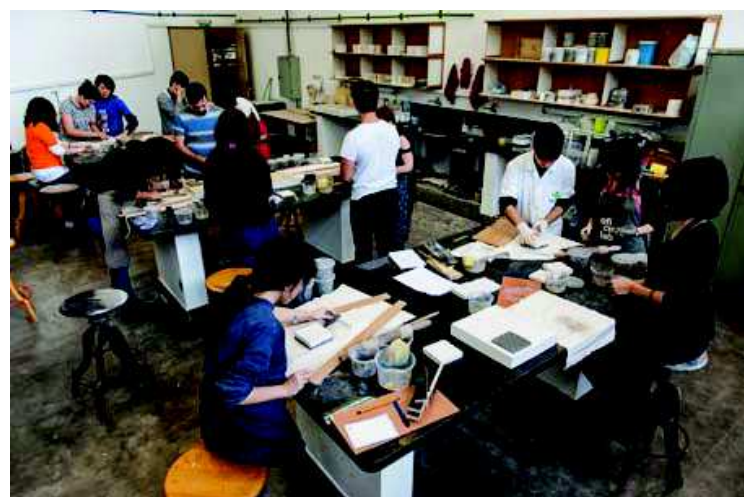

Figura 1a: Alunos durante o workshop. Fonte: Foto de Ana Paula Maldonado.

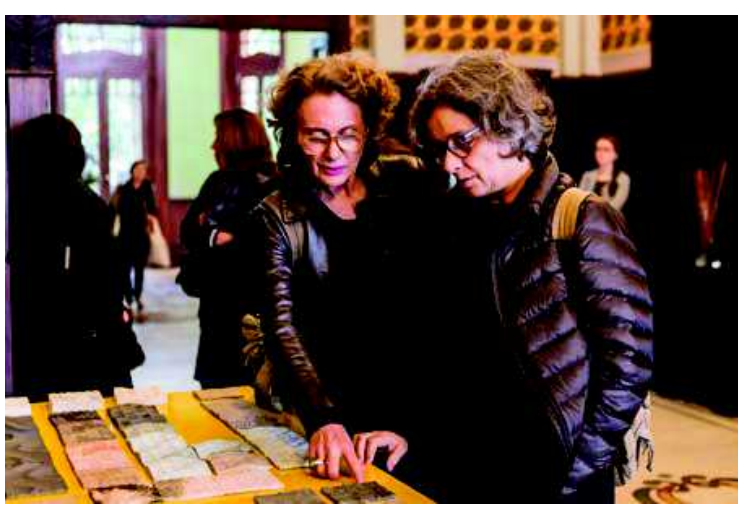

Figura 1b: Exposição dos resultados durante a semana. de debates. Fonte: Foto de Ana Paula Maldonado.

\footnotetext{
${ }^{6}$ Doutorandas do PPG FAU USP em Design e Arquitetura, fazem parte da equipe do projeto de pesquisa.

7 NextMaterials: a experiência do Politecnico di Milano (tradução nossa).

8 Disponível em: $<w w w . n e x t m a t e r i a l s . i t>$
}

setembro de 2016, que presenciaram a demonstração dos protótipos e de alguns moldes gerados durante o workshop e manifestaram interesse e curiosidade quanto ao processo, aos resultados e à possibilidade de replicação do workshop. Bianca Fragnani, gerente de marketing da empresa parceira deste workshop também foi enfática em relação à qualidade e potencial dos resultados obtidos. A avaliação do processo de trabalho e de aprendizado foi realizada mediante debate com alunos e professores no último dia do workshop. A aceitação de seu modelo e aprovação da experiência e dos resultados foram unânimes, havendo ainda franca manifestação de incentivo para que esta modalidade de curso de curta duração e alta intensidade de conteúdos seja replicada. Atualmente os protótipos gerados estão em fase de catalogação para inserção no acervo de materiais da FAU USP, o Materialize.

\section{Multiplicidade DE PONTOS DE Vista SOBRE MATERIAIS, DESIGN, ARQUITETURA E ECONOMIA CRIATIVA}

O ciclo de debates teve início no dia 19 pela manhã com a apresentação da proposta do projeto e do acervo de materiais para o design e arquitetura, Materialize, pela professora Denise, que também apresentou a palestra "Dados da economia criativa no Brasil: Panorama da área de design", juntamente com Iana Garófalo Chaves e Maria do Rosário Gonçalves Mira6 . Os dados foram apresentados a partir dos relatórios da Unctad (2010) e Unctad (2014), FIRJAN (2014) e Diagnóstico do Design Brasileiro (2013). Ainda pela manhã a professora Barbara proferiu a palestra NextMaterials: l'esperienza del Politecnico di Milano ${ }^{7}$. Discorreu sobre a spin off NextMaterials ${ }^{8}$, nova empresa ligada à universidade e ao grupo de pesquisa do mesmo nome que tem como objetivo criar inovação com valor econômico e comercial, trabalhando com empresas como Eletrolux, Luxotica, Benetton, ou empresas de menor porte, como a Nanosurface, especializada em tratamento superficial. A professora Del Curto apresentou também o seu laboratório de pesquisa Making Materials Lab., mostrou suas pesquisas em nanotecnologia aplicada aos têxteis e à joalheria, à smart packaging e tratamentos de ar. 
9 Professora dos cursos de arquitetura e design da FAU USP, com pesquisas na interface dessas duas áreas do conhecimento.

10 Doutoranda do PPG FAU USP em Design e Arquitetura, faz parte da equipe do projeto de pesquisa.

${ }^{11}$ A inovação no design baseada nos materiais (tradução nossa).

12 Os materiais "inovadores" tem eficiência funcional e tecnológica, trazem novos estímulos formais e expressivos e inúmeros referenciais simbólicos (tradução nossa).

13 Disponível em: $<$ www.d3olab.com>

14 Disponível em: $<$ www.litracon.hu/en>

15 Disponível em: $<$ www.luccon.com>

16 Disponível em: $<$ www.lamellux.com>.

17 Disponível em: $<$ www.luminoso.at $>$.

18 Disponível em: $<$ www.legnopan.com>

19 Disponível em: $<$ www.technogel.it/ index. php?id=185>

20 Disponível em: $<$ www.villanileonello.com/ sugherotessuti.html>.

${ }^{21}$ Disponível em: $<$ www. bencore.it/>.

22 Disponível: <em www.effepimarmi.it>
A sessão da tarde foi aberta pela Profa. Dra. Cibele Taralli ${ }^{9}$, que apresentou a palestra "Pesquisa em materiais no design e arquitetura com foco na economia criativa", juntamente com Célia Moretti Arbore ${ }^{10}$, introduzindo alguns aspectos da relação da arquitetura com os materiais, a partir do pressuposto que esta é uma área do conhecimento e atuação prática complexa, que compreende vários segmentos e oportunidades criativas e de produção/ execução. Dentro do contexto da economia criativa a professora teceu algumas considerações acerca do papel inventivo inerente à atividade projetual, da possibilidade de inovação por ideias (projetos), suas aplicações, desenvolvimento e execução em espaços e produtos, pois a arquitetura se expressa formal e construtivamente pela materialidade.

Mostrou dados estatísticos sobre a concentração de empregos e unidades criativas em arquitetura concentradas nas regiões sul e sudeste e em menor incidência distribuídas nas capitais do país, e abordou a questão de como e onde designers e arquitetos buscam informações sobre materiais para aplicação em seus projetos e produtos. Em seguida apresentou e analisou alguns exemplos de criação de novos produtos nacionais decorrentes de pesquisa e iniciativas em universidades brasileiras.

Logo após, a professora Barbara apresentou a palestra L'innovazione nel design basata sui materiali $i^{11}$, em que desmistificou a inovação como unicamente associada aos aspectos tecnológicos e apresentou três pontos a serem considerados quando se fala de um material inovador: tecnológicos, expressivo e linguagem do projeto. Neste sentido, destacou os materiais projetados sob demanda, uma realidade atual, a inovação por transferência tecnológica de um segmento produtivo a outro, a revisitação de materiais tradicionais com novos usos ou aspectos técnicos e, por último, a importância da comunicação das propriedades dos materiais para se criar inovação. Para a professora, "I materiali "innovativi" hanno efficienza funzionale e tecnologica, danno nuovi stimoli formali ed espressivi e svariati strumenti simbolici"12. Na primeira categoria, dos materiais sob demanda, apresentou como exemplos o $d 3 o^{13}$, material com absorção de choque, o LitraCon (Light transmiting concrete) ${ }^{14}$, o Luccon $^{15}$, o Lamellux ${ }^{16}$ (misto de madeira e resina) e o Luminoso $^{17}$, este último um material feito em madeira e fibra ótica. Para explicar o conceito de transferência tecnológica apresentou o caso do titânio, que era originalmente utilizado para aplicações militares, aeroespaciais e atualmente está presente em diversos produtos tais como óculos, joias, rodas de carros, telefones celulares; ou o Alusion ${ }^{18}$, painéis de espuma de alumínio estabilizada, ou o Technoge ${ }^{19}$, originariamente da área médica e atualmente utilizado no setor calçadista para solados de tênis, ou mouses, luminárias, entre outros. Outro caso interessante apresentado foi o tecido de cortiça, da empresa Villani Leonello ${ }^{20}$, desenvolvido para o uso no setor calçadista e de moda. Para os materiais tradicionais com novas propriedades destacou-se a Bencore ${ }^{21}$, que produz painéis compostos superleves com estrutura interna feita em forma alveolar de colmeias e que mudam suas propriedades estruturais e estéticas dependendo do material de revestimento. A comunicação talvez seja o item de inovação mais desconhecido, uma vez que apresenta "velhos materiais" com nova roupagem, permitindo novos usos, como no caso do Rivestone ${ }^{22}$ - um material composto de pedrinhas de mármore ou naturais unidas por uma resina 


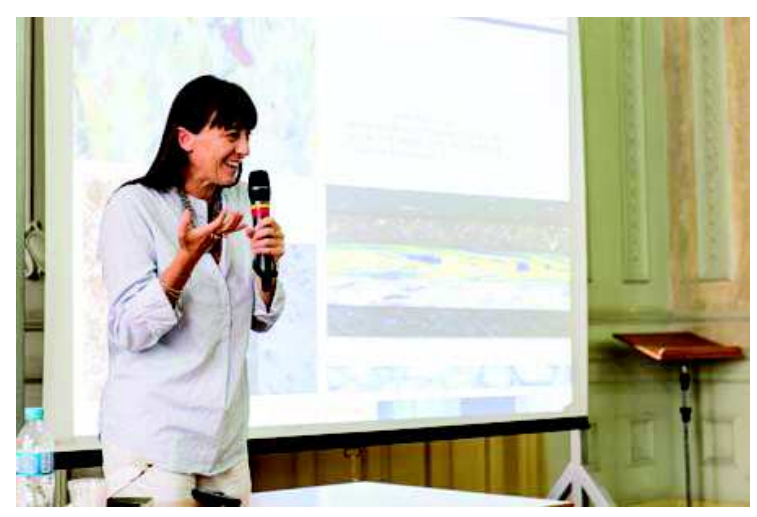

Figura 2a: Barbara Del Curto durante sua palestra. Fonte: Fotos de Ana Paula Maldonado

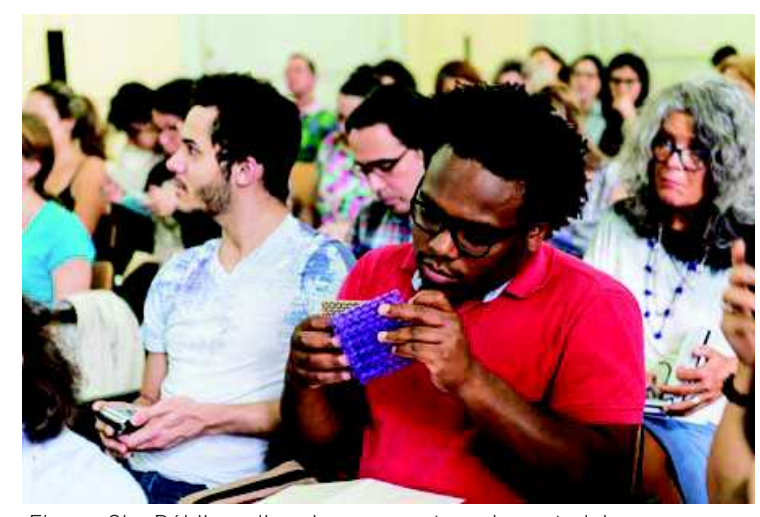

Figura 2b: Público olhando as amostras de materiais. Fonte: Fotos de Ana Paula Maldonado.

\section{$\frac{\text { I I } 4}{\text { ì }}$}

${ }^{23}$ Coleção de livro infantis inclusivos com texto de Lia Zatz, ilustrações de Luise Weiss e design de Wanda Gomes. colorida ou transparente. Cada um dos materiais que o compõem não tem, em si, nenhuma inovação tecnológica, mas a forma como é apresentado e comunicado permite novos usos devido às suas novas propriedades estéticoformais. 0 público presente neste dia pode também experienciar as amostras de alguns materiais trazidos pela professora bem como outros similares nacionais que fazem parte do acervo Materialize da FAU USP, que conta com amostras de materiais voltados para o design de produto, gráfico, de embalagem e de arquitetura.

Melissa Ferraz Barbosa, da Diretoria de Ciência e Tecnologia, Ideias e Conceitos da Natura, apresentou a palestra sobre pesquisa em materiais locais para produtos sustentáveis feita pela empresa e conjecturou sobre seu possível rebatimento para o desenvolvimento de embalagens.

Em seguida, Monica Evangelista, Gerente Comercial de Polipropileno da Braskem, apresentou a experiência de parceria Universidade/ Empresa no desenvolvimento do desafio Braskem de Design, que na edição 2015 teve como vencedores os alunos da FAU Robson Nakata e Henrique Corazza, do Curso de Design, e Luiza Landert, do de Arquitetura.

O encerramento das atividades do primeiro dia deu-se com a palestra da designer gráfica Wanda Gomes, da WG Produto, responsável pelo desenvolvimento do sistema Braille BR, nova tecnologia de impressão em braile por meio de aplicação de verniz sobre o suporte. Wanda apresentou os desafios de desenvolvimento de uma tecnologia inclusiva a partir de pesquisa acadêmica com futura aplicação em produtos de mercado para pequenas empresas. Como exemplo, apresentou a coleção Adélia ${ }^{23}$, na qual foi aplicado o sistema Braile BR. Empresas de vários portes, desde internacionais até um pequeno escritório, puderam mostrar sua perspectiva de inovação em materiais para o design, o que abriu espaço para ampliar a discussão acerca do potencial de inovação social que pode ser resultado da pesquisa em materiais aplicada ao design e à arquitetura. Os outros quatro dias de evento contaram com mesas temáticas, descritas a seguir. 
${ }^{24}$ Especialista em design de joias desde janeiro de 1986, é designer credenciada pela ADOR, Associazione Designers Orafi, de Milão, Itália, desde 1993, diretora de Design da AJESP, Associação dos Joalheiros do Estado de São Paulo.

${ }^{25}$ Catálogo disponível em: <http:// www.electaweb.it/mostre/ scheda/titani-preziosi-tratecnologia-e-ornamentomilano-triennale/it>.

\section{JOALHERIA E TÊXTIL E MODA: PESQUiSA EM NOVOS MATERIAIS E PROCESSOS}

No dia 20 ocorreram as mesas de debate sobre Joalheria (período matutino) e Têxtil e Moda (período vespertino). A mesa de debate Joalheria: Pesquisa em novos materiais e processo, discutiu a possibilidade de inserção de novos materiais e tecnologias no tradicional mercado joalheiro brasileiro. Contou com a mediação de Engracia Costa Llaberia ${ }^{24}$, da AJESP, Associação Joalheira do Estado de São Paulo, e a participação de José Pascoal Costantini, presidente do IBGM (Instituto Brasileiro de Gemas e Metais) e proprietário da Costantini Joias, dos designers Eliânia Rossetti, da 3D soluções, Michel Striemer, do atelier California 120 e Rodrigo Ferreira Silva, do SENAI SP.

A professora Barbara abriu com a palestra "Gioielli - Titani Preziosi", na qual apresentou o projeto "Gioie e Colori", financiado pela região da Lombardia, que teve como objetivo a criação de uma nova cadeia de produção para a criação de joias em titânio. 0 projeto envolveu diversos atores, além do Politecnico di Milano, tais como as empresas Titalia, NanoSurface, Vacuum Surtec, Taigher, Bama e Eurometal. Também contou com a participação de renomados designers italianos, que criaram as peças utilizando a tecnologia SLM - Select Laser Melting - para fabricação digital de pequenas séries. A pesquisa nesse novo processo produtivo aplicado ao design de joias consistiu em compreender as limitações tecnológicas do material e do processo para o uso neste segmento, considerando as complexidades das formas possíveis de serem produzidas, a precisão dos detalhes mesmo em dimensões maiores, possibilidades de cortes e formas complexas, também chamadas de formas impossíveis. Ainda foram exploradas diferentes texturas e tratamentos superficiais. Os aspectos de coloração foram obtidos a partir do uso de oxidação anódica, para a qual foi desenvolvida uma escala cromática com dois tipos distintos de acabamento. Também foi feita a aplicação do acabamento TriHard, que torna a superfície mais resistente à corrosão. 0 resultado final da pesquisa foi apresentado na mostra "Titani Prezziosi: tra tecnologia e ornamento"25, que ocorreu na Trienalle di Milano, em 2010 na qual os designers convidados apresentaram suas criações de joias em titânio.

José Pascoal Costantini apresentou os objetivos e as realizações da instituição. Também fez relato sobre desenvolvimento de novos produtos em sua fábrica de joias, uma das maiores e mais tradicionais do ramo no Brasil. Questionado sobre o uso de materiais alternativos aos metais e pedras preciosas na joalheria contemporânea, destacou a qualidade passageira destes materiais alternativos e ressaltou no setor da joalheria a necessidade de resistir ao tempo, a busca da qualidade de objetos de tesouro, de valor simbólico e afetivo guardado em um objeto perene que passa de geração a geração.

Eliânia Rossetti apresentou em sua fala o que há de mais novo nos programas de modelagem digital 3D voltados para joia e também as interfaces com processos de manufatura digital, que abrangem desde a usinagem de moldes de cera para fundição até os processos de sinterização a laser seletivo de pós metálicos. Mostrou caminhos e potencialidades para a criação de joias inovadoras, com formas extremamente complexas possíveis graças a estas tecnologias digitais. Rodrigo Ferreira Silva, do SENAI, divulgou sua produção e seus prêmios nacionais e internacionais. Em sua apresentação, ressaltou a 


\begin{tabular}{ll} 
I I6 & $\begin{array}{l}26 \text { Proprietária da Editora } \\
\text { especializada em Moda e } \\
\text { Design Estação das Cores e } \\
\text { presidente da ABEPEM. }\end{array}$ \\
\cline { 1 - 1 } ¿̇ &
\end{tabular}

Figura 3: Mesa de debate sobre joalheria no dia 20 de setembro, na sala dos espelhos (FAU Maranhão). Fonte: Fotos de Ana Paula Maldonado. importância do trabalho do projeto associado à indústria joalheira e a necessidade de aliar qualidade e produtividade nos projetos de novos produtos. Michel Striemer relatou sobre seu processo criativo em ambientes diversos, que envolveu o desenvolvimento de novos produtos para empresas como HStern, com definição de público, valor e lançamento, até as experiências de um design mais autoral desenvolvido no atelier Califórnia 120. Um debate acalorado entre membros da mesa e audiência demonstrou divergências quanto à definição de joalheria e bijuteria. Engracia posicionou-se diante da necessidade de diferenciar a classificação de joia e bijuteria adotada tanto pela indústria como pelo setor do comércio, e em feiras e eventos nacionais e internacionais.

As investigações e busca de conceitos para novos produtos a partir de peças fabricadas com materiais nobres são as únicas aceitas como joias por representantes do ramo joalheiro e do setor fabril nacional. Já artistas e designers defendem e consideram como joias peças ornamentais resultantes experimentações e produções com materiais tradicionais ou não, na busca de linguagens singulares.

A pesquisa desenvolvida pela professora Barbara com titânio despertou grande interesse da plateia, que se surpreendeu com a adoção de processos altamente tecnológicos aplicados no desenvolvimento de novos materiais para joalheria, associado com o design de joias com estes materiais. Foi possível constatar o rigor da pesquisa, os critérios para classificação cromática das amostras, capacidade de replicação pela indústria e a qualidade técnica, ergonômica e estética dos produtos desenvolvidos.

À tarde houve o debate sobre Têxtil e Moda, mediado por Kathia Castilho ${ }^{26}$ da ABEPEM, Associação Brasileira de Ensino e Pesquisa em Moda. O setor de Têxtil e Moda tem se reinventado a cada estação, com novos materiais e processos produtivos que unem alta tecnologia, performance e sustentabilidade. O Brasil é um país que possui uma grande quantidade de fibras naturais, nem sempre bem aproveitadas ou conhecidas pelos profissionais atuantes no mercado, principalmente no que diz respeito à sua aplicação industrial. 0 desenvolvimento de pesquisas que permitam conhecer melhor o potencial das fibras brasileiras, bem como pesquisas em alta

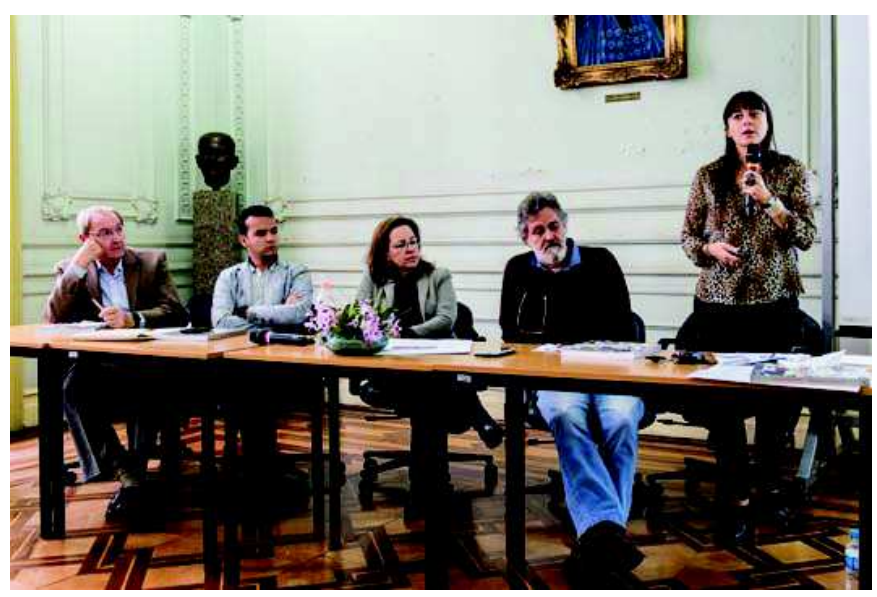


${ }^{27}$ Pesquisadora da EACH/USP especializada no estudo de fibras vegetais brasileiras para aplicações têxteis e no estudo de reciclagem têxtil (processos e produtos) para produção de fios, não tecidos, compósitos e outros produtos que possam ser inseridos na cadeia têxtil.

28 Pesquisadora da EACH/USP especializada no desenvolvimento de novos materiais (Biomateriais), desenvolvimento de têxteis técnicos (Médicos, compósitos, eletrônicos, bactericida) micropartículas e nanopartículas para incorporação em têxteis.

29 Professor pesquisador do curso de Design da FAU USP e coordenador do curso de Design FAU Mackenzie.

30 Proprietário da Lavintage Desenvolvimentos Têxteis, especialista em processos de lavanderia e de produção industrial com uso de nanotecnologia.

31 Disponível em: <https:// youtu.be/jLgICkufHiO>. tecnologia que melhoram a performance dos tecidos tem tido grande impacto no desenvolvimento de novos produtos de moda conhecidos como Made in Brazil. Também no design, diversos novos produtos utilizam e se beneficiam das pesquisas em têxteis para aplicação em mobiliário, interiores, automóveis, equipamentos técnicos, uniformes, entre outros.

Os debates confrontaram os aspectos de sustentabilidade no setor, a dificuldade de transferência de tecnologias e materiais desenvolvidos na universidade para o setor produtivo brasileiro e os aspectos de especificação de produtos têxteis para diversos segmentos. Contou com a participação da Profa. Dra. Julia Baruque Ramos ${ }^{27}$, da EACH/USP, que apresentou pesquisa sobre fibras têxteis brasileiras, entre elas o tururi, que está sendo utilizado para o desenvolvimento de novos contraplacados para uso em mobiliário. Também foi apresentada a pesquisa da Profa. Dra. Silgia Costa ${ }^{28}$, também da EACH/USP, sobre o desenvolvimento de tecidos medicinais à base de quitosana. 0 Prof. Dr. Marcelo Oliveira ${ }^{29}$ apresentou o desenvolvimento feito por sua empresa para a roupa do astronauta brasileiro Marcos Pontes, enfatizando a dificuldade de integração para especificação de materiais para uniformes no setor aéreo em parceria com profissionais de design de moda. Fernando Meneghetti ${ }^{30}$, com sua experiência em processos têxteis de lavanderia, debateu sobre a inovação que tem ocorrido neste segmento, com a incorporação de processos de gestão de resíduos e redução do consumo de energia e água, pouco perceptível aos consumidores, mas de grande impacto em todo o ciclo têxtil. A professora Barbara apresentou o projeto Textile Vivant ${ }^{31}$, desenvolvido pelo Politecnico di Milano, sob encomenda da Triennale di Milano. Este projeto apresenta o percurso, a experiência e o resultado da pesquisa do design têxtil que, além dos aspectos do design, mostra uma dimensão histórica, artística e tecnológica dos tecidos e dos produtos têxteis. 0 projeto conjugou treze empresas italianas de diversos setores e usuários de produtos têxteis, quatro centros de pesquisa universitários e sete renomados designers e artistas plásticos. O resultado desta pesquisa foi apresentado em uma mostra na própria Triennale em setembro de 2014. Cada um dos materiais e instalações, além das questões de técnicas da pesquisa, como os mapas do desenvolvimento da cadeia têxtil, foram apresentados e debatidos pela professora.

Um ponto levantado pelas pesquisadoras brasileiras foi a necessidade de as empresas nacionais investirem em todo o processo de pesquisa, em uma visão de longo prazo. Há uma tendência no mercado nacional de se considerar a produção de pesquisa das universidades públicas como algo "sem custo", ou seja, "de todos", e as empresas muitas vezes entendem que a parceria para a transferência de tecnologia não implica em nenhum investimento de sua parte em novas pesquisas na universidade. A apresentação Textile Vivant, da professora Barbara, suscitou bastante interesse da plateia por enfatizar um novo modo de apresentação de resultados de pesquisa, além dos tradicionais papers em periódicos científicos. Os modelos de parcerias utilizados para os projetos do Politecnico di Milano com as empresas também foram discutidos à luz da dificuldade apresentada pelas pesquisadoras brasileiras em dar continuidade para a transferência de tecnologias em suas pesquisas. A professora Barbara também salientou que o Politecnico faz questão de registrar as patentes de seus desenvolvimentos para garantir a propriedade intelectual, firmando seu pioneirismo no cenário internacional. Entretanto, aponta que os lucros obtidos pela universidade com a venda das patentes são ínfimos. 
Figura 4: Da esq. para a dir.: Júlia, Marcelo, Barbara, Fernando, Kathia, Silgia e Denise.

Fonte: Fotos de Ana Paula Maldonado.
32 Membro da Academia

Internacional de Cerâmica (IAC Suíça), docente colaboradora

do Departamento de Artes

Visuais da Escola de

Comunicações e Artes (ECA-

USP). É uma das Coordenadoras

do Grupo Terra de Pesquisas.

33 Diretor da ABCERAM e professor da Escola Politécnica da USP na engenharia de materiais.

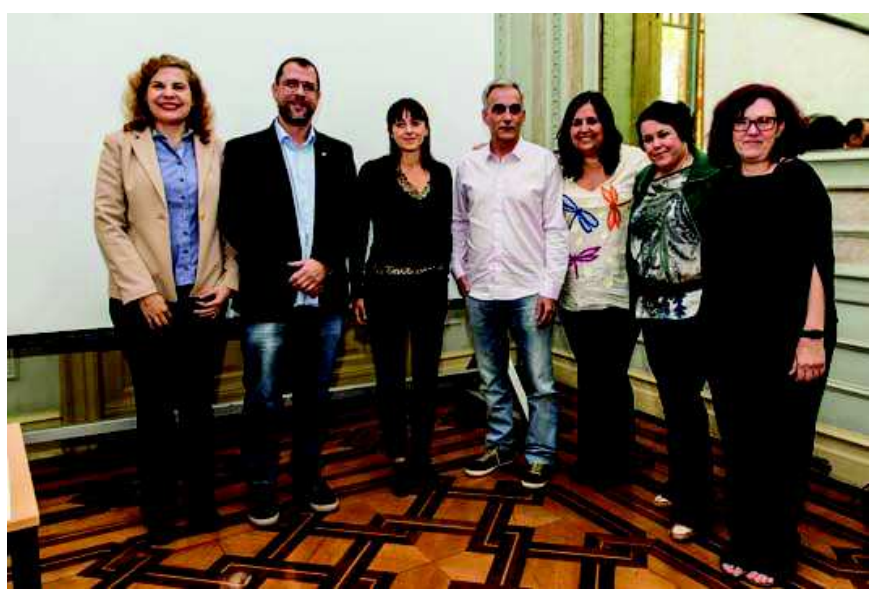

Normalmente, elas são cedidas para as empresas parceiras a custo zero ou próximo a isso por alguns anos, para garantir retorno de seus investimentos na pesquisa. Caso não tenha havido uma parceria empresarial, a universidade disponibiliza a tecnologia em sua spin off NextMaterials.

\section{DESIGN E MATERIAIS - EXPERIMENTAÇÕES E PESQUISA EM CERÂMICA}

O setor de cerâmica é bastante diversificado, apresentando tanto desenvolvimentos altamente tecnológicos quanto desenvolvimentos de produtos do cotidiano. Em virtude da complexidade dos processos produtivos e das demandas técnicas e de desempenho, o investimento em pesquisas dos aspectos estético-formais se dão de maneira mais esporádica, sendo que grande parte dos investimentos neste quesito tratam dos aspectos estéticos de superfície, tais como nos revestimentos cerâmicos, na louça de mesa e nos objetos ornamentais. Se a escala da indústria limita as investigações sobre a expressividade da matéria, muitas vezes, é nas investigações artísticas que isso se desenvolve. Os resultados destas pesquisas feitas no meio artístico têm a capacidade de servir de inspiração para o desenvolvimento de peças de design cerâmico e adaptação para produção em escala industrial. A mesa foi mediada pela professora da FAUUSP Cristiane Aun Bertoldi e contou com a participação de Bianca Fragnani, Profa. Dra. Norma Tenenholz Grinberg ${ }^{32}$, Ricado Minoru Gubo e Prof. Dr. Samuel Toffoli ${ }^{33}$.

O professor Toffoli apresentou as realizações da Associação Brasileira de Cerâmica que, há mais de sessenta anos, organiza o Congresso Brasileiro de Cerâmica - um congresso científico que reúne representantes dos variados setores da cerâmica desde a cerâmica artística, a produção de cerâmica tradicional até à engenharia de materiais avançados. Convidou a audiência a participar dos novos eventos a fim de buscarem um canal de troca de conhecimentos e possibilidades de trabalhos conjuntos. 0 professor ainda apresentou o curso de Engenharia de Materiais da Escola Politécnica da USP, com destaque para algumas pesquisas ali realizadas de utilização de resíduos em formulações de vidrados, próprios para trabalhos em parceria com pesquisas em design. 
${ }^{34}$ Tecnólogo em Ambiental e professor de Cerâmica da Escola Senai Mario Amato.

${ }^{35}$ Gerente de marketing do Grupo Fragnani.

36 SENSORIAL Oxide - as propriedades sensoriais e a percepção das cerâmicas técnicas (tradução nossa).

Figura 5: Da esq. para a dir. Ricardo, Bianca, Cristiane, Norma e Barbara.

Fonte: Fotos de Ana Paula Maldonado.
Ricardo Minori Gubo ${ }^{34}$ apresentou a instituição, evidenciando o potencial de utilização de suas instalações e o suporte de seu pessoal técnico qualificado para realização de análises e desenvolvimento de novos materiais voltados para inovação.

Bianca Fragnani ${ }^{35}$ destacou as estratégias das empresas do grupo no desenvolvimento de novos produtos, apresentou os novos investimentos em tecnologia e em processo para garantia de controle da qualidade de produto, do ponto de vista técnico e funcional e, em relação ao design de produtos, ressaltou o uso de impressora jato de tinta e imagens HD para garantir variedade de padrões decorativos na paginação de superfícies que simulam a aparência de materiais naturais como pedras e madeiras.

A professora Norma Tenenholz Grinberg mostrou resultados de investigações do Grupo Terra de Pesquisa, em particular o desenvolvimento de 184 massas cerâmicas com cores e texturas variadas para uso em arte e design. Também apresentou um panorama do $47^{\text {th }}$ Congresso da IAC - International Academy of Ceramics, no qual artistas e designers exploraram as características do material cerâmico, levando-as ao limite na construção de obras e projetos, com especial atenção para trabalhos para uso em arquitetura e em espaços públicos.

A professora Cristiane realizou uma breve apresentação do workshop Design e Materiais: experimentações com cores e texturas para criação de produtos cerâmicos já descrito acima.

A professora Barbara abriu o evento com a palestra SENSORIAL Oxide - Le proprietà sensoriali e la percezione dei ceramici tecnici ${ }^{36}$. Este trabalho é o resultado de uma tese em colaboração com a l'Ecole des Mines di Saint Etienne - França, e se propôs a identificar um modelo mental para as cerâmicas técnicas. Para isso, apresentou o instrumento de pesquisa Test Napping, no qual os usuários descrevem sua percepção aos estímulos apresentados por pequenas amostras de diferentes materiais dispostos em uma mesa denominada Sensotech, que é capaz de criar os mapas a partir das modalidades escolhidas: hepática, visual ou ambas. Estas ferramentas de pesquisa se mostraram muito interessantes para a aplicação em outros tipos de materiais e podem ser futuramente utilizadas em pesquisas em parceria com a universidade.

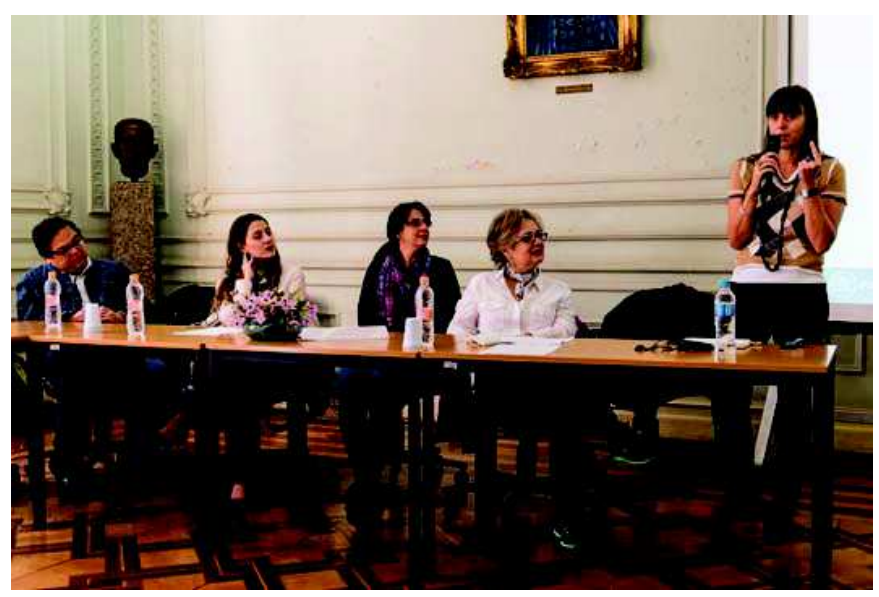




\section{O PAPEL DOS MATERIAIS NA CONCEPÇÃO E PRODUÇÃO DE MÓVEIS}

À tarde o debate sobre mobiliário foi mediado pelo designer André Midões, pósgraduando da FAUUSP e contou com a presença dos designers Ana Carolina Toyama $^{37}$, da Oppa, e Paulo Biacchi ${ }^{38}$, do Studio Fetiche Design, e de Monica Evangelista, da Braskem.

O design de mobiliário no Brasil é reconhecido tradicionalmente pelo uso de madeiras nobres, como também por painéis de madeira reconstituída oriundas na sua maioria de manejo sustentável. A pesquisa e o emprego de outros materiais, como os de composição metálica; plásticos, fibras e compósitos podem apresentar potencial de inovação neste segmento, associados ou não a tecnologias de produção e processos.

As discussões transitaram nas possibilidades de introdução de inovações em materiais na cadeia produtiva de móveis; na associação destes a novas tecnologias (maquinário, processos, mão de obra, automação), até o uso de materiais convencionais ou naturais, associados ou modificados estruturalmente, ou na sua composição formal, que tem sido investigado em universidades e centros de pesquisa, visando promover a diferenciação e inovação no setor produtivo de móveis no Brasil.

A palestra L'innovazione nei materiali per il design del mobile ${ }^{39}$, da professora Barbara, destacou a relação entre a forma dos produtos com os materiais e tecnologias empregados na sua fabricação. Em uma perspectiva histórica, iniciando em Thonet e seu inovador processo de curvatura da madeira e de montagem e desmontagem de suas cadeiras, chegando até a "madeira líquida" utilizada pela empresa $\operatorname{Tecnaro}^{40}$, que pode ser produzida a partir de resíduos e é fornecida em pellets para ser injetada. A professora discutiu como um mesmo material, ao longo do tempo, pode apresentar grande desenvolvimento tecnológico que tem forte impacto na estrutura, na forma e na superfície dos produtos de design.

empresa Oppa, head de designers externos e curadora do portfólio da empresa.

38 Proprietário do Studio Fetiche Design.

39 Inovação dos materiais para o design de móveis (tradução nossa).

40 Disponível em:

$<$ www.tecnaro.de/english/ arboform.htm?section=arboform $>$.
A apresentação da professora Barbara mostrou um percurso evolutivo sobre as relações de desenvolvimento dos móveis, associado às matérias primas e processos de produção, chegando às possibilidades contemporâneas desse quadro. Destacou a importância do conhecimento atualizado de pesquisa e inovação em materiais com capacidade para alimentar o setor de mobiliário e ressaltou que muitas vezes um material tradicional quando associado ao uso de processo tecnológico inovador faz com que suas características e potencialidades mudem.

Já os setores profissionais representados pelo escritório Fetiche Design e a OPPA que atuam em projetos e produção de móveis voltados para classes $A$ e $B$ mostraram-se receptivos quanto a introdução de inovações no setor moveleiro, mas consideraram que há restrições de operacionalização prática em função dos investimentos necessários em maquinário, programas de software, serviços e infraestrutura na cadeia produtiva para a implementação dessas inovações. Também foi debatida a importância do acesso a dados organizados e atualizados sobre propriedades técnicas e formais de materiais para o design de móveis, assim como a necessidade de atuação dos designers no segmento de móveis populares, faixa de maior volume de vendas no mercado brasileiro e que 


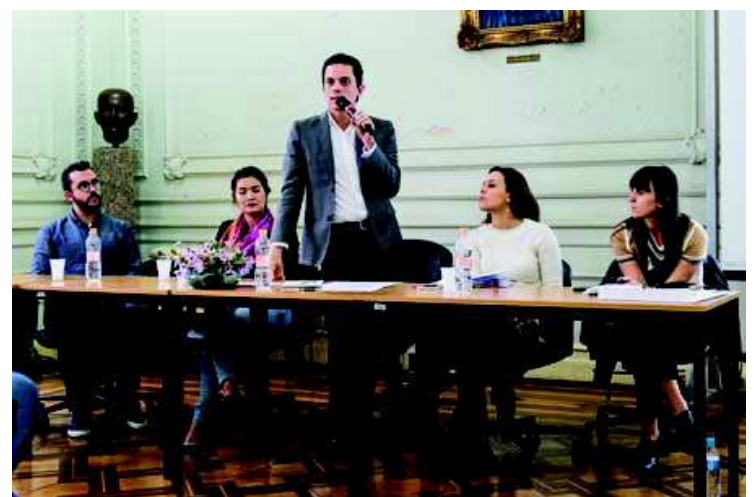

Figura 6a: Da esq. para a dir.: Paulo, Ana, André, Mônica, Barbara. Fonte: Fotos de Ana Paula Maldonado

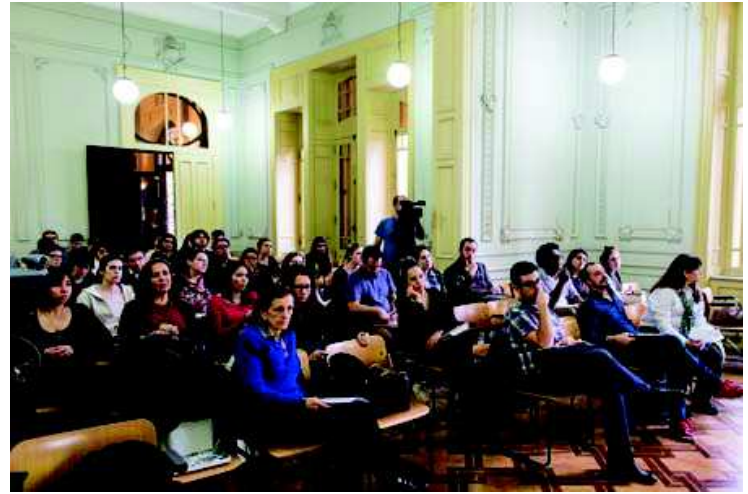

Figura 6b: Plateia.

Fonte: Fotos de Ana Paula Maldonado.
41 Sócia Proprietária da Pande Design, agência especializada no desenvolvimento de embalagens.

42 Produtos horto frutícolas frescos que se apresentam lavados e desinfetados, cortados ou não e que mantêm as caraterísticas da matéria prima devido à atmosfera protetora da embalagem em que se encontram. apresenta baixos padrões de qualidade formal e de durabilidade de produtos. A Braskem também se mostrou aberta a trabalhos e parcerias conjuntas e colaborativas entre os setores - universidade, mercado, e atuação profissional para o desenvolvimento de tecnologias e processos.

\section{MATERIAis E PROCESSOS PARA INOVAÇÃO EM DESIGN DE EMBALAGENS}

No dia 22 os debates foram dedicados ao setor de embalagem e arquitetura.

O segmento de embalagens é muito dinâmico e as pesquisas em materiais tem garantido melhor desempenho, aumento do "shelf life" e melhorias nos processos produtivos e de distribuição dos produtos. Estas pesquisas normalmente são desenvolvidas pela área de engenharia de embalagens ou engenharia de materiais, chegando aos designers em forma de especificações, normalmente feitas pelas próprias empresas contratantes dos serviços de projeto. Por outro lado, os materiais tipicamente brasileiros têm dificuldade de encontrar espaço no competitivo mercado de embalagens. Mediada por Gisela Schulzinger ${ }^{41}$, presidente da ABRE, Associação Brasileira de Embalagem, estes foram alguns dos tópicos discutidos nesta mesa, que envolveram questões como o desenvolvimento de novos materiais, aspectos de sustentabilidade, redução do uso de materiais e características do desenvolvimento de novos materiais locais para o uso em pequenas e médias empresas.

Barbara apresentou neste dia a palestra MANTELLO: Materiali e packaging a Mantenimento Termico per il risparmio energetico nelLa LOgistica e nel trasporto di prodotti alimentari freschi, desenvolvido pelo Politecnico di Milano em parceria com a empresa Ghelfi Ondulati (produtor de papelão ondulado). 0 projeto mostra o potencial de desenvolvimento de pesquisa em parceria entre universidade e empresas. Um novo material foi desenvolvido para a aplicação na embalagem de materiais com mudança de fase para a manutenção térmica na logística de produtos de $4^{\text {a }}$ gama ${ }^{42}$. O novo material desenvolvido foi testado em caminhões frigoríficos de transporte e também em pontos de venda, garantindo menor perda de frio durante a logística desse produto em comparação com as embalagens em papelão ondulado convencionais. 
Figura 7: Da esq. para a dir. Gisela, Paula, Elisa, Albertoni, Silvia e Barbara.

Fonte: Fotos de Ana Paula Maldonado

\section{Professora da Universidad Autónoma Metropolitana (México), na cadeira de Embalagem, autora de diversos livros. \\ ${ }^{44}$ Professora da Universidade Cruzeiro do Sul e responsável pelo blog Embalagem Sustentável, é mestre pela FAU USP na área de concentração Design e Arquitetura. \\ 45 Disponível em: <http:// www.teses.usp.br/teses/ disponiveis/16/16134/tde- 10072014-162359/pt-br.php>.}

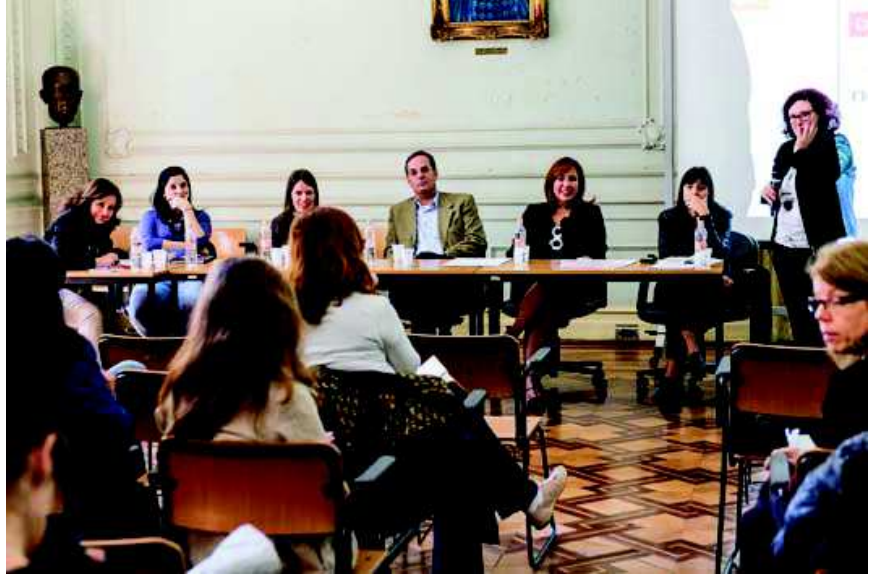

A presença da Profa. Msc. Silvia Oropeza Herrera ${ }^{43}$, professora visitante da UAM na FAU USP, foi importante para enfatizar as diferenças no desenvolvimento de materiais para a produção de embalagens para pequenas e médias empresas pela universidade em parceria com artesãos locais. Nos projetos mexicanos o design de embalagem e o desenvolvimento de materiais locais utiliza processos de design para qualificar, a partir da embalagem, a produção artesanal de diversos gêneros alimentícios típicos do país, tais como o Cacau e a Tequila. A designer Elisa Quartim Barbosa ${ }^{44}$ apresentou sua pesquisa de mestrado sobre a percepção dos consumidores acerca das questões ambientais comunicadas nas embalagens de alimentos orgânicos ${ }^{45}$ e a dificuldade de se escolher um material mais sustentável para empresas pequenas e médias, que dependem dos materiais commodities disponíveis para baixos volumes de produção. A mesa contou ainda com a participação de importantes empresas brasileiras: a Natura, representada pela designer Paula Matara Sampaio, e a Braskem, representada por Albertoni Bloisi Neto, especialista no desenvolvimento de mercado para o setor de embalagem. Paula apresentou os desafios no desenvolvimento de novas embalagens com redução de materiais a cada novo projeto e os processos de design utilizados pela empresa para cumprir essas metas. A Braskem apresentou seus materiais direcionados para o segmento de embalagens e os desafios da empresa no segmento para os próximos anos.

\section{Novos materiais, Novos espaços EM Arquitetura}

A mesa mediada pela professora Cibele Taralli discutiu que o campo da arquitetura possui várias subáreas de atuação, o que leva à variação no papel dos materiais em relação a constituição de espaços e ambientes dos pontos de vista da pesquisa, da seleção e do uso de produtos acabados no projeto e na execução das soluções.

A apresentação da professora Barbara enfatizou que arquitetos e designers precisam saber sobre materiais e evidenciou a contribuição das materiotecas para as atividades de projeto, construção ou produção. A complexidade de conhecimentos e informações técnicas com linguagem e conteúdo organizado e 
46 Professora do departamento de Tecnologia na Faculdade de Arquitetura da USP

47 Professor do departamento de Projeto na Faculdade de Arquitetura da USP.

48 Arquiteto Diretor da GCP Arquitetura e Urbanismo. aplicado ao uso e a experimentação em projetos são fundamentais, em função da diversidade crescente de oferta e desenvolvimento de produtos e materiais disponíveis para a arquitetura.

A disponibilidade de busca e consulta em banco de dados virtuais, que incorpore informações do fabricante, incluindo inovações e experiências em pesquisas, e ao mesmo tempo fornecendo dados sensoriais e expressivos dos materiais representou grande melhoria na pesquisa e seleção de materiais realizada por arquitetos que antes dependia de suas coleções de catálogos e arquivos.

Foram apresentados cases de acervos de materiais no Brasil e no mundo começando pelo Politecnico di Milano (Materiali e Design) e terminando com o Materialize da FAUUSP. As possibilidades de consulta nestes acervos beneficiam as atividades projetuais e de pesquisa.

A experiência em ensino, pesquisa e extensão desenvolvida na Universidade de São Paulo foi apresentada na palestra da professora Cláudia Terezinha de Andrade Oliveira ${ }^{46}$ da FAUUSP que enfocou o papel dos materiais e processos de montagem na inovação e desempenho dos sistemas construtivos. Mostrou a experiência de projeto, construção e montagem do protótipo da ECCO House residência de baixo impacto ambiental, energeticamente autossuficiente - que tem no sol a base do seu desenho e desempenho.

Também trazendo visão da Universidade de São Paulo, o professor Paulo Eduardo Fonseca de Campos $^{47}$, da FAUUSP, trouxe à tona a discussão sobre a passagem de processos manufaturados para os prototipados digitalmente nos sistemas construtivos e as mudanças acarretadas na configuração da arquitetura, como resultado do pensar e do produzir nestas tecnologias, diretamente relacionadas aos materiais utilizados. Os resultados arquitetônicos e os sistemas construtivos por ele apresentados mostram o vínculo direto entre o uso de materiais e as técnicas de execução, dos pontos de vista formal, funcional, de desempenho técnico, construtivo e ambiental.

Já experiências na atuação profissional em arquitetura foram destacadas pelo arquiteto Sergio Coelho ${ }^{48}$ que apresentou projetos arquitetônicos corporativos

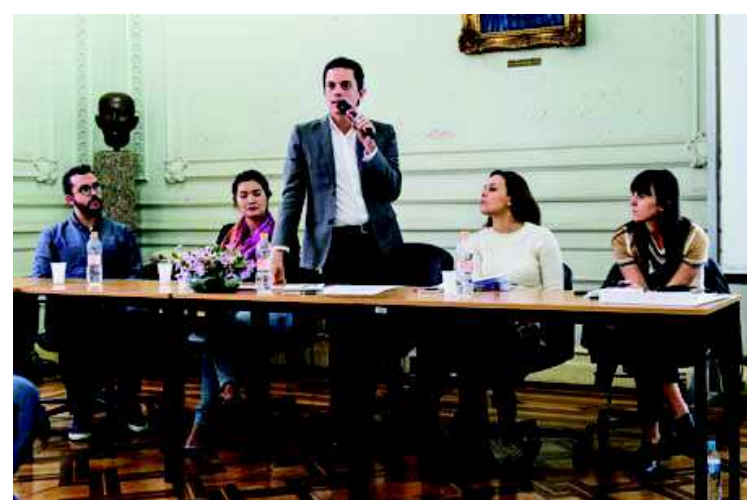

Figura 8a: Amostra do LitraCon.

Fonte: Fotos de Ana Paula Maldonad

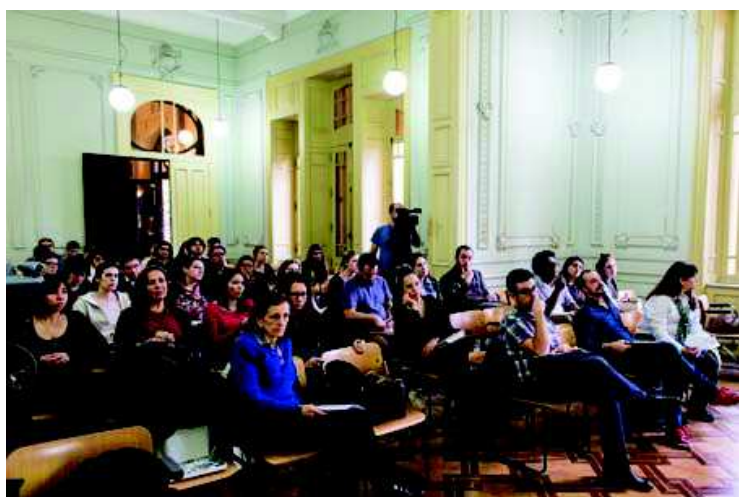

Figura 8b: Debatedores da mesa de arquitetura. Fonte: Fotos de Ana Paula Maldonado. 


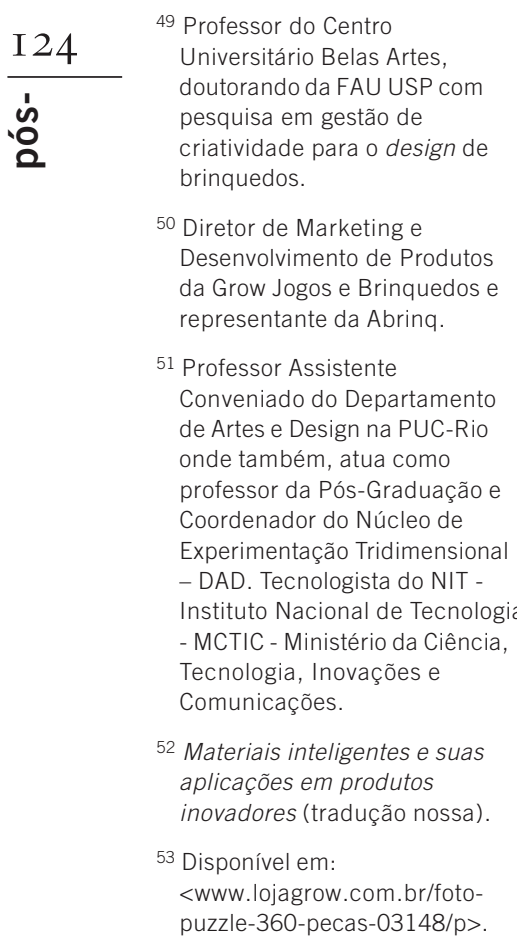

49 Professor do Centro versitário Belas Artes, esquisa em gestão de criatividade para o design de

Diretor de Marketing Desenvolvimento de Produtos Grow Jogos e Brinquedos

Professor Assistente ém, atua como dimensiona io da Ciência, Tecnologia, Inovações e

Materiais inteligentes e suas aplicações em produtos Disponível em: $<$ www.lojagrow.com.br/foto-
puzzle-360-pecas-03148/p> premiados, resultado de pesquisa e aprendizado em criação e execução de soluções inovadoras apoiadas na tecnologia construtiva e dos materiais, com eficiência e qualidade estética. Abordou a relação direta entre pesquisa e seleção de materiais e produtos para a construção com os resultados de excelência obtidos em soluções arquitetônicas ambientalmente sustentáveis, com uso e funções atendidas, segundo as exigências espaciais, tecnológicas e estéticas.

\section{BRINQUEdos E JOgOS: DESAFIOS PARA A INOVAÇÃO EM MATERIAIS}

O segmento de brinquedos e jogos no Brasil tem cada vez mais se afastado de suas origens culturais. Dominado por produtos licenciados importados, os brinquedos e materiais brasileiros têm sido cada vez mais relegados ao segmento de produto artesanal, com pouca distribuição no mercado brasileiro. Apesar do grande número de lançamentos anuais anunciados pelas empresas, grande parte desses brinquedos apresentam apenas adaptações de velhos produtos a novos personagens licenciados do cinema ou televisão, empregando basicamente MDF, papel e plástico.

Por outro lado, existem pesquisas em materiais funcionais e produtos tecnológicos que exploram o potencial dos materiais inteligentes para serem aplicados em diversos segmentos, inclusive em brinquedos e jogos. Diante deste cenário, a mesa de debates Brinquedos e Jogos que ocorreu no último dia do evento trouxe à cena as questões relativas aos desafios de inovação em materiais no mercado brasileiro para grandes e pequenas empresas e o uso de novas tecnologias de impressão 3D para a fabricação digital no setor. Mediada pelo Prof. Msc. Alexandre Perroca Castro ${ }^{49}$, a mesa contou com a participação de João Nagano Junior ${ }^{50}$ da Abrinq, Associação Brasileira dos Fabricantes de Brinquedos, Achilles Simioni, designer proprietário da empresa de brinquedos Kitopeq, e do Prof. Dr. Jorge Lopes ${ }^{51}$, professor da PUC-Rio e pesquisador do NIT/MCTIC.

A professora Barbara abriu este último encontro com a palestra "Materiali intelligenti e loro applicazioni nei prodotti innovativi"52, mostrando possibilidades para a aplicação de materiais inteligentes a novos projetos e alguns exemplos para o segmento de brinquedos, com o uso de materiais de custo acessível. De ligas com memória de forma até materiais fotocrômicos ou termo crômicos, a professora apresentou uma discussão sobre o potencial de inovação proveniente dos materiais inteligentes aplicados ao segmento.

João Nagano trouxe os desafios da GROW e da Abrinq para o desenvolvimento de inovação, apresentando o novo modelo de negócios da empresa, que terceirizou totalmente sua produção. Também destacou o uso de sistemas digitais de produção para os quebra-cabeças que permitem personalização, o FotoPuzzel ${ }^{53}$.

Achilles Simioni mostrou os desafios de uma empresa de pequeno porte no desenvolvimento de novos brinquedos no Brasil. Apresentou também o desenvolvimento de materiais especificamente para seus produtos e o desafio de inovar com simplicidade. O Prof. Dr. Jorge Lopes apresentou seu trabalho 
no Núcleo de Experimentação Tridimensional, com a aplicação de impressão 3D para a criação de kits de brinquedos feitos pelas próprias crianças.

Destacou os novos paradigmas de produção e perspectivas futuras, nos quais os produtos serão impressos na casa das pessoas e os materiais serão projetados como commodities para sistema de produção individualizado, seguindo o mesmo desenvolvimento que ocorreu com os computadores nos últimos vinte e cinco anos. 0 debate contou também com a presença dos designers argentinos Alejandro Perren, proprietário da Hand atelier, estúdio situado em Buenos Aires, e Dolores Delucchi, professora da FADU e membro da "Camara argentina de la industria del juguete", que puderam problematizar o mercado argentino em comparação com o brasileiro e os aspectos da pesquisa em materiais nos dois países.

\section{CONSIDERAÇÕES FINAIS}

O ciclo de debates e o workshop evidenciaram o contraste dos modelos voltados para inovação italiano e brasileiro, nos quais o primeiro conta com parcerias frutíferas entre setores empresariais, a universidade, profissionais da indústria criativa e parte de financiamento do governo. Neste modelo, há compromisso de divulgação da produção destes conhecimentos gerados a partir de exposições e publicações voltadas ao público em geral e ainda se destacam a profusão de patentes obtidas, a visibilidade dos resultados gerados pelas parcerias nas criações de designers e arquitetos apresentadas em feiras e exposições mundialmente relevantes. 0 segundo modelo evidencia a desarticulação entre pesquisa, indústria e profissionais da economia criativa. No Brasil, encontram-se iniciativas de empresas que adotam como estratégia de diferenciação e de valorização de mercado a pesquisa em novos materiais. Pesquisas são desenvolvidas dentro das universidades, divulgadas em eventos científicos para um público acadêmico, podem ou não contar com financiamento de agências do governo. Designers e arquitetos mantém em seus escritórios mostruários de novos materiais e catálogos divulgados em feiras nacionais e internacionais e não tem acesso aos resultados de pesquisas experimentais realizadas na universidade. 0 potencial de inovação brasileiro existe e o movimento para efetiva articulação entre os setores da indústria, universidade e profissionais criativos sugere ser este um caminho para sua conquista.

\section{REFERENCIAS}

CENTRO BRASIL DESIGN. Diagnóstico do Design Brasileiro (2014). Brasília: CBD/Apex/MDIC, 2014. Disponível em: http://www.cbd.org.br/wp-content/uploads/2013/01/ Diagnostico_Design_Brasileiro_Web.pdf [Acesso em 20 de junho de 2016].

FIRJAN. Mapeamento da Indústria Criativa no Brasil. Rio de Janeiro: FIRJAN, 2014. Disponível em: http://publicacoes.firjan.org.br/economiacriativa/mapeamento2014/\#/3/zoomed [Acesso em 10 de agosto de 2016].

UNCTAD. UNITED NATIONS EDUCATIONAL, SCIENTIFIC AND CULTURAL ORGANIZATION. Creative Economy: A Feasible Development Option.Report 2010. Disponível em: http://unctad.org/fr/Docs/ ditctab20103_en.pdf [Acesso em 18 de junho de 2014]. 
UNCTAD. UNITED NATIONS EDUCATIONAL, SCIENTIFIC AND CULTURAL ORGANIZATION. Creative economy report 2013 special edition: widening local development pathways. Disponível em http://www.unesco.org/culture/pdf/creative-economy-report-2013-en.pdf [Acesso em 18 de unho de 2014].

Realização: 5 a 23 de setembro de 2016

Local: Faculdade de Arquitetura e Urbanismo da Universidade de São Paulo (FAU-USP), São Paulo, SP.

\section{Denise Dantas}

Faculdade de Arquitetura e Urbanismo. Universidade de São Paulo (FAU-USP). São Paulo, SP.

CV: http://lattes.cnpq.br/7636937300587505

dedantas@usp.br

\section{Cristiane Aun Bertoldi}

Faculdade de Arquitetura e Urbanismo. Universidade de São Paulo (FAU-USP). São Paulo, SP.

CV: http://lattes.cnpq.br/1791567263251867

craun@usp.br

\section{Cibele Haddad Taralli}

Faculdade de Arquitetura e Urbanismo. Universidade de São Paulo (FAU-USP).

São Paulo, SP.

CV: http://lattes.cnpq.br/6016190566941978

cibelet@usp.br 